\title{
Long-term effectiveness of pingers on a small population of finless porpoises in Japan
}

\author{
Masao Amano ${ }^{1, *}$, Miku Kusumoto $^{1}$, Misaki Abe ${ }^{1}$, Tomonari Akamatsu ${ }^{2,3}$ \\ ${ }^{1}$ Graduate School of Fisheries and Environmental Sciences, Nagasaki University, Nagasaki 852-8521, Japan \\ ${ }^{2}$ NRIFS, Fisheries Research Agency, Fukuura, Kanazawa, Yokohama, Kanagawa 236-8648, Japan \\ ${ }^{3}$ CREST, Japan Science and Technology Agency, Gobancho, Chiyoda-ku, Tokyo 102-0075, Japan
}

\begin{abstract}
Finless porpoises Neophocaena spp. are under pressure from various anthropogenic impacts due to their coastal habitat. Net fishery bycatch is considered a major risk for the populations around Japan, and mitigation measures are required. We carried out a long-term study to assess the efficiency of acoustic pingers in reducing the encounter rates of narrow-ridged finless porpoises with fishing nets. We used a passive ultrasonic event recorder (A-tag) to obtain acoustic encounter rates of echolocating finless porpoises and compared results for the presence and absence of pinger transmissions in Omura Bay, Japan, over two 8-mo periods (2011 and 2012). Encounter rates were significantly lower during periods when pingers were in operation, but the effect of pingers decreased with time. By the eighth month of the study in each study year, the number of encounters during the ensonified period was greater than that during periods without pingers, suggesting habituation. When pingers were reactivated at the study site after 4 mo of silence, the encounters with the active pingers returned to the lower level observed at the beginning of the experiment. These results reveal that the pingers effectively induce avoidance in porpoises, but that this effectiveness only lasts for a few months, which is likely due to habituation which could be mitigated by alternating periods of several months of silence between periods of active pinger use.
\end{abstract}

KEY WORDS: Bycatch · Pinger · Neophocaena asiaeorientalis $\cdot$ Small cetacean · Bioacoustics

\section{INTRODUCTION}

Of the various anthropogenic impacts on populations of small coastal cetaceans, which include habitat loss and degradation, and collision with vessels, bycatch in net fisheries is considered the most serious in many habitats (Read et al. 2006). Various measures to reduce bycatch in terms of regulations of scale and period have been proposed, e.g. banning of the fishery, time/area fishery closure, improvement of fishing gear, and use of deterrent devices. The effectiveness of these measures depends on the type of fishery involved, as well as the biological characteristics of the target species. In circumstances in which a ban on a certain type of fishing gear or closure of the fishery is not appro-

${ }^{*}$ Corresponding author: m-amano@nagasaki-u.ac.jp priate, acoustic deterrent devices might be an effective measure for reducing bycatch.

The effectiveness of acoustic pingers to mitigate bycatch of several cetacean species has been documented previously (e.g. harbor porpoises Phocoena phocoena, Kraus et al. 1997, Palka et al. 2008, Larsen \& Eigaard 2014; common dolphins Delphinus delphis and beaked whales, Barlow \& Cameron 2003, Carretta et al. 2008, Carretta \& Barlow 2011; franciscanas Pontoporia blainvillei, Bordino et al. 2002), however, this effectiveness is not evident for bottlenose dolphins Tursiops truncatus (Cox et al. 2004, McPherson et al. 2004). Although no evidence of habituation has been reported for large-scale applications of pingers in gillnet fisheries (Palka et al. 2008, Carretta \& Barlow 2011), other experimental

() The authors 2017. Open Access under Creative Commons by Attribution Licence. Use, distribution and reproduction are unrestricted. Authors and original publication must be credited. 
studies have suggested the occurrence of habituation to pinger alarms (Kraus 1999, Cox et al. 2001, Carlström et al. 2009), and Dawson et al. (2013) stated that habituation might occur for inshore and resident populations. Habituation could increase the risk of bycatch by increasing the chances of porpoises approaching the nets, although there is no conclusive evidence to support this (Dawson et al. 2013).

Finless porpoises Neophocaena spp. are primarily coastal odontocetes that are distributed in inshore waters and several large rivers in southern and eastern Asia. Their usual habitats are waters shallower than the $50 \mathrm{~m}$ isobath with soft-bottom substrates (Shirakihara et al. 1994, Amano et al. 2003, Jefferson \& Hung 2004). Due to their coastal habitat, finless porpoises are considered to be under serious threat from anthropogenic activities in many regions (Jefferson \& Hung 2004, Reeves \& Wang 2012, Wang \& Reeves 2012, Shirakihara \& Shirakihara 2013). Porpoises in the Yangtze River, China, in particular, have an estimated $5 \%$ annual decline rate, with bycatch in nets being one of the major causes of mortality (Wang 2009). In Japan, based on an interview survey, over 200 porpoises were estimated to be taken incidentally every year in Ariake Sound; this is $>5$ times more than the potential biological removal (PBR) calculated for this population (Shirakihara \& Shirakihara 2013). Therefore, effective mitigation measures for bycatch are required for finless porpoises.

There is a small population of 200 to 300 narrow-ridged finless porpoises $N$. asiaorientalis inhabiting Omura Bay, western Kyushu, Japan (Fig. 1) (Yoshida et al. 1998). Finless porpoises of this population are well differentiated from adjacent populations by skull morphology (Yoshida et al. 1995), mtDNA haplotype frequency (Yoshida et al. 2001), and calving season (Shirakihara et al. 1993), which suggests limited immigrations from adjacent populations. Further, only a single mtDNA haplotype was detected in this population (Yoshida et al. 2001), indicating lower genetic diversity. All these facts suggest that this population is vulnerable to demographic and environmental stochastic factors. Bycatch of finless porpoises in gillnets and set nets does occur in Omura Bay, with the reported number of bycatches being 4 to 5 animals annually for the past 5 yr. However, the actual number might be greater than 10 individuals, which would exceed the PBR that is estimated at approximately 4 animals (M. Amano unpubl. data).

There are many small-scale gillnet and set net fisheries operating along the coast of Omura Bay, and a fishery ban or closure, either here or elsewhere in Japan, is usually unacceptable, as fishermen and the Japanese government are less conscious of marine mammal conservation and reluctant to adopt strong management measures without unequivocal evidence of threats. Thus, we consider that use of acoustic deterrent devices, i.e. pingers, is the most plausible measure to reduce bycatch. To evaluate the longterm effectiveness of acoustic pingers for mitigating bycatch of finless porpoises, a 2-yr experiment using a passive acoustic echolocation event recorder was carried out in Omura Bay.

\section{MATERIALS AND METHODS}

The experiment was carried out at a small set net that was placed off Osaki Peninsula in Omura Bay, Japan (Fig. 1) from April 2011 to December 2012. The study area was approximately 10-15 m deep with a muddy bottom that gradually inclined offshore. A passive acoustic event detector (A-tag, Marine Micro Technology; Akamatsu et al. 2005, 2010), which detects ultra-sonic pulses, was deployed $40 \mathrm{~m}$ offshore

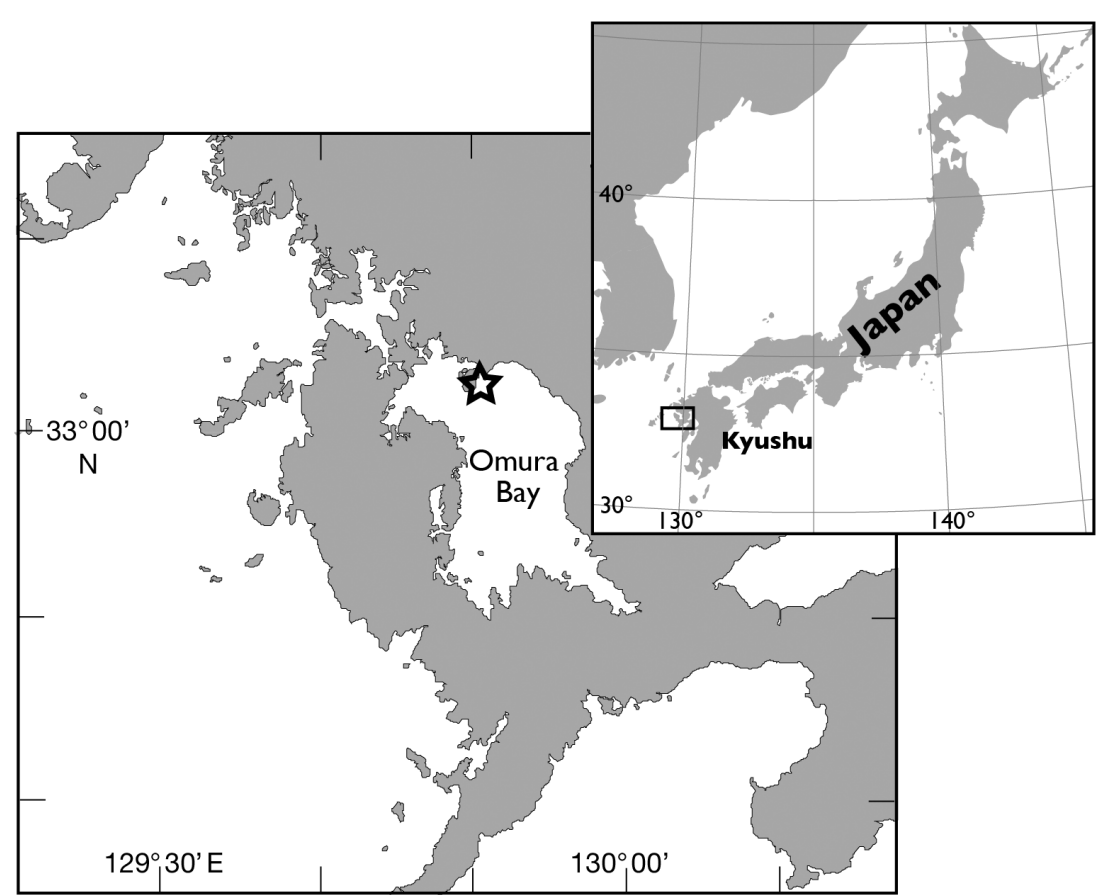

Fig. 1. Study site in Omura Bay, Japan 
from the set net at $1.5 \mathrm{~m}$ depth, attached to a buoy (Fig. 2). The position of the A-tag was determined after consideration of the detection range (about $100 \mathrm{~m}$ for off-axis clicks of finless porpoise; Akamatsu et al. 2010), the recommended maximum spacing for the pingers used $(200 \mathrm{~m}$; European Commission 2004), and the distance at which fishing operation can be achieved unobstructed. The daily encounters of finless porpoise obtained from the A-tag data fluctuated (see 'Results'), which implies that this site represents only a part of the home range of finless porpoises.

AQUAmark100 pingers (AQUATEC Group) were used as an acoustic deterrent. These are designed to reduce the bycatch of harbor porpoises in net fisheries and have been reported to effectively decrease harbor porpoise bycatch under experimental conditions (Larsen et al. 2013). Since the acoustic characteristics of finless porpoise echolocation clicks are similar to those of harbor porpoises (Akamatsu et al. 1998), we selected this pinger for our experiment. AQUAmark 100 pingers generate wideband frequency-modulated sound between 20 and $160 \mathrm{kHz}$ with a typical source pressure level of $145 \mathrm{~dB}$ re $1 \mu \mathrm{Pa} @ 1 \mathrm{~m}$ for 200-300 ms and a random interval of 5-30 s. Two pingers were deployed on the set net (Fig. 2); one was attached on the upper rope of the guide net (approximately $80 \mathrm{~m}$ from the A-tag) and the other was attached on the rope at the entrance of the enclosure net (approximately $50 \mathrm{~m}$ from the Atag). These positions were selected because finless porpoises are usually caught in set nets by becoming entangled in the guide net or drowned in the trap net connected to the enclosure net. Both pingers were set at a depth of approximately $30 \mathrm{~cm}$. The pingers were ensonified for approx. $2 \mathrm{wk}$, followed by a silent period of approx. $2 \mathrm{wk}$; this approx. $4 \mathrm{wk}$ cycle was repeated from April to December 2011, after which we set a 4 mo silent period and then began the $2 \mathrm{wk}$ on/ $2 \mathrm{wk}$ off cycle again at the end of April 2012 to examine whether the habituation that may have occurred during the first year trial period is mitigated. We had to remove the buoy containing the A-tag from the water several times due to tropical storms. After the completion of each year's experiments the pingers were tested to ensure they were still working properly.

A single encounter was defined as a series of porpoise click trains in which the interval between adjacent trains was $<3$ min, because finless porpoises rarely suspend emitting echolocation clicks for more than $200 \mathrm{~s}$ (Akamatsu et al. 2007).

We assessed the efficacy of pingers using a generalized linear model (GLM). The response variable was the number of encounters recorded each day with a negative binomial error structure, and the predictor variable was pinger status (on or off). We included the interaction between pinger status and the number of days from the beginning of the experiment (hereafter, day number), because the effectiveness of the pingers appeared to decrease with time. We performed GLMs for the 2011 and 2012 season data separately using the glm package in $\mathrm{R} 3.2 .2$ (R Development Core Team 2015).

\section{RESULTS}

The number of encounters during ensonified periods was lower than that during adjacent silent periods for the first 4 mo of the study in both years (Fig. 3). However, the encounters in the ensonified period increased thereafter, and after 7 mo and

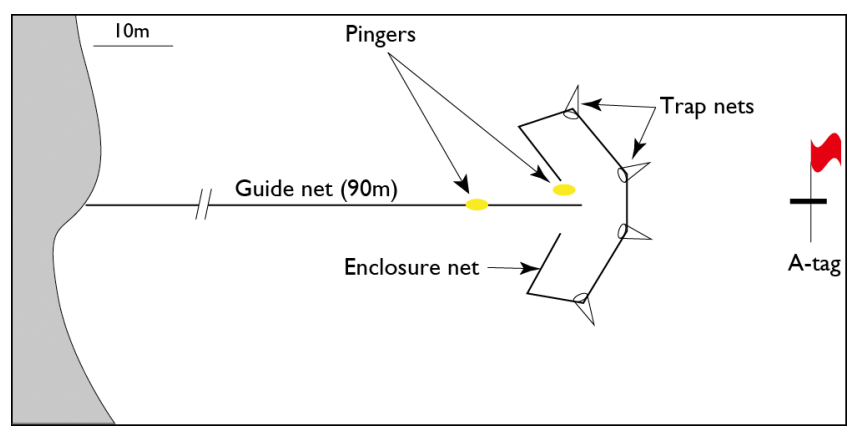

Fig. 2. Experimental setup of the A-tag and pingers at a set net

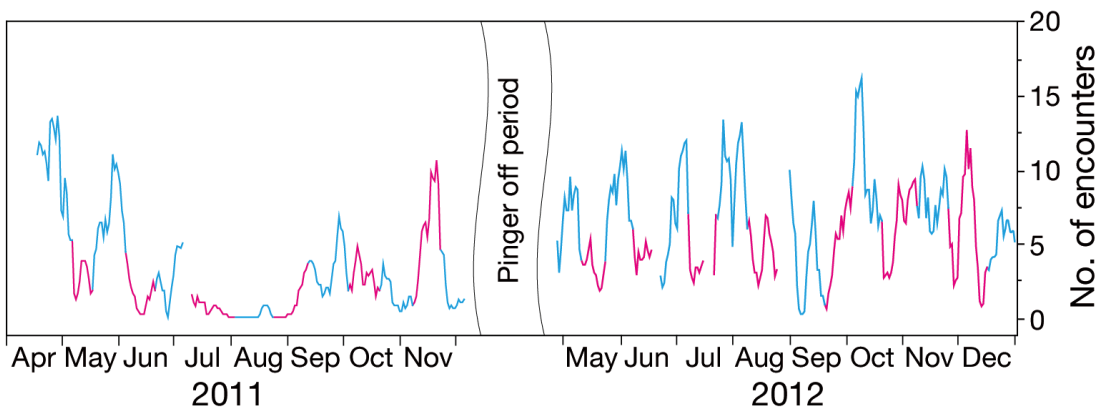

Fig. 3. Fluctuation in the number of encounters of finless porpoises detected by the A-tag. The simple moving average of a 5-d interval is shown. Blue line indicates the period without pingers (silent period) and red line indicates that with pingers. The breaks in the data indicate the period during which the buoy with the A-tag was retrieved due to tropical storms 
reached a similar level to, or even exceeded, that in the silent period (Fig. 3). The overall seasonal trend in finless porpoise encounters differed between the 2 years, with the obvious decrease in summer of 2011 not observed during 2012 (Fig. 3).

The GLM revealed a significant negative effect of the presence of pingers on daily encounters in both years $(p<0.05$; Table 1$)$. The interaction between active pingers and day number was positive for both years, which indicates that encounters during the ensonified period increased with time elapsed. There was a negative correlation between inactive pingers and day number in the first year but not in the second.

No bycatch occurred in this set net during the 2-yr experiment.

\section{DISCUSSION}

The GLM for the 2 years clearly indicated that the presence of pingers significantly decreased the number of encounters of finless porpoises with the set net (Table 1), implying that pingers may be effective in reducing bycatch of finless porpoises in the gillnet fisheries, as is evident for harbor porpoises (Dawson et al. 2013). The present study suggests that the pingers designed for harbor porpoises are effective for finless porpoises as well.

The interaction between the presence of pingers and day number was positive in both years (Table 1), which indicates that pinger efficacy decreased over time. The interaction between absence of pingers and day number was negative in the first year but not significant in the second year (Table 1). This reflects the difference in seasonal trend of finless porpoise encounters between the 2 years as shown in Fig. 3. Despite this difference, the change in the effect of

Table 1. Generalized linear model parameters for encounters of finless porpoises with active/inactive pingers. Variables include pinger status (on/off) and days since the beginning of the experiment (day)

\begin{tabular}{|lrrr|}
\hline Variable & Estimate & SE & p-value \\
\hline 2011 season & & & \\
Pinger on & -2.467 & 0.394 & $<0.001$ \\
Pinger on $\times$ day & 0.007 & 0.002 & 0.003 \\
Pinger off $\times$ day & -0.010 & 0.002 & $<0.001$ \\
2012 season & & & \\
Pinger on & -1.042 & 0.230 & $<0.001$ \\
Pinger on $\times$ day & 0.003 & 0.001 & 0.004 \\
Pinger off $\times$ day & -0.0004 & 0.001 & 0.663 \\
\hline
\end{tabular}

active pingers was similar in both years. After the first 4 or $5 \mathrm{mo}$, differences in the number of encounters between the periods with active pingers and silent periods became smaller, and encounters in the active periods actually exceeded those during the adjacent silent periods after 7 mo of study (Fig. 3). This might have been caused by the habituation of porpoises to the pinger signals. After long periodical transmission of deterrent sounds, porpoises might have been attracted to the pingers, or the 'dinner bell effect' could have occurred (Dawson 1994, Kraus et al. 1997, Bordino et al. 2002). The fact that encounters increased just after pingers were intiated in October and November 2011 also supports this effect (Fig. 3). Although there is no direct evidence of depredation from the fishing nets, finless porpoises are known to be opportunistic feeders that prey on various schooling fishes that are usually caught by net fisheries (Shirakihara et al. 2008) and are occasionally caught in the gill and set nets (Shirakihara \& Shirakihara 2013, M Amano unpubl. data). This implies that finless porpoises might be attracted to fishing gear when it is detected in the distance.

The GLM revealed a significant effect of pingers in both years with possible habituation occurring as mentioned above. A decrease in encounters with active pingers occurred again after the 4 mo of silence, indicating that the effectiveness of pingers resumed in the second year (Fig. 3), suggesting that habituation to the pingers was mitigated by the several months of silence. Habituation is one of the possible drawbacks of using pingers, as this can impair their effectiveness (Kraus 1999, Cox et al. 2001, Carlström et al. 2009). The present study is the first to report that habituation might be mitigated by refraining from using pingers for a certain period of time, and advocates the usefulness of pingers. Since this was based only on a single experiment for a single species, further research is required to determine whether this is the case for other species. The $2 \mathrm{wk}$ on/2 wk off cycle of pinger activation in the current experiment could affect the time needed to establish habituation as well as the time to mitigate it. The continuous ensonification of the pingers might have established habituation quicker and hindered its mitigation. To determine the effective application of pingers, further studies are required to establish under what conditions and for what periods it is necessary to develop and diminish the habituation via a more controlled experiment.

Finless porpoises show strict habitat preferences, i.e. waters shallower than $50 \mathrm{~m}$ with soft-bottom substrates (Kasuya \& Kureha 1979, Shirakihara et al. 
1992, Amano et al. 2003, Jefferson \& Hung 2004), and their populations tend to be isolated with limited gene flow (Chen et al. 2010, Yoshida et al. 2001, Zheng et al. 2005, Li et al. 2011, Ju et al. 2012). These local populations are easily fragmented and their numbers negatively affected by various anthropogenic factors. A clear decline in population size has been detected in the Yangtze River, China, and Seto Inland Sea, Japan, with bycatch considered a main factor responsible for this decline (Kasuya et al. 2002, Zhao et al. 2008, Mei et al. 2012, Wang \& Reeves 2012). In the Ariake Sound, Japan, approximately 200 to 300 porpoises, corresponding to 5 to $10 \%$ of the population, were estimated to be caught annually as bycatch in gillnet fisheries (Shirakihara \& Shirakihara 2013). Reducing the threat of bycatch is of high priority for the conservation of finless species, and the application of pingers is one promising method for mitigating incidental mortality.

In Japan, small-scale gillnet fisheries are widely operated in coastal waters by one or a few fishermen using small boats. These operations are opportunistic depending on the resource availability and tide, but the occurrence of bycatch tends to show seasonal patterns in many areas, e.g. the majority of the bycatch is reported in spring through early summer in Omura Bay and in fall through winter in Ariake Sound (Shirakihara \& Shirakihara 2013, M. Amano unpubl. data). The present study suggests that an appropriate level of sound transmission exists. Overexposure to sound could be worse than silence, which might attract porpoises to the fishing gear. Thus, limited use of pingers only during periods of large bycatch would effectively reduce the incidence of bycatch without developing persistent habituation. The actual implementation strategy needs to be carefully considered, since apparent increases in bycatch rate due to improper use or malfunctioning pingers have been reported (Palka et al. 2008, Carretta \& Barlow 2011).

The majority of phocoenid species are coastal species and many populations are similarly affected by bycatch, including harbor porpoises and vaquitas Phocoena sinus (Rojas-Bracho et al. 2006, Reeves et al. 2013). Results from the present study demonstrating that habituation to the pinger signal can be mitigated by refraining from using pingers for a certain period suggest a possible effective way to further the conservation of these species. However, further study of the most efficient regime of pinger usage for different species and populations is required to maximize the effect of pingers in reducing bycatch mortalities.
Acknowledgements. We thank H. Yamaguchi for his considerable assistance in the experiment. Izumi Marine Service, H. Goto, and R. Leeney helped us in the field. T. Yamamoto gave us valuable suggestions on statistics. This study was financially supported by the Pro Natura Foundation, Japan. The research protocol of this study was approved by the Animal Care and Use Committee, Nagasaki University and Fisheries Agency, Japan, according to the Fisheries Resources Protection Law.

\section{LITERATURE CITED}

Akamatsu T, Wang D, Nakamura K, Wang K (1998) Echolocation range of captive and free-ranging baiji (Lipotes vexillifer), finless porpoise (Neophocaena phocaenoides), and bottlenose dolphin (Tursiops truncatus). J Acoust Soc Am 104:2511-2516

Akamatsu T, Matsuda A, Suzuki S, Wang D and others (2005) New stereo acoustic data logger for free-ranging dolphins and porpoises. Mar Technol Soc J 39:3-9

Akamatsu T, Teilmann J, Miller LA, Tougaard J and others (2007) Comparison of echolocation behaviour between coastal and riverine porpoises. Deep-Sea Res II 54:290-297

Akamatsu T, Nakamura K, Kawabe R, Furukawa S, Murata H, Kawakubo A, Komaba M (2010) Seasonal and diurnal presence of finless porpoises at a corridor to the ocean from their habitat. Mar Biol 157:1879-1887

Amano M, Nakahara F, Hayano A, Shirakihara K (2003) Abundance estimate of finless porpoises off the Pacific coast of eastern Japan based on aerial surveys. Mammal Study 28:103-110

Barlow J, Cameron GA (2003) Field experiments show that acoustic pingers reduce marine mammal bycatch in the California drift gillnet fishery. Mar Mamm Sci 19:265-283

* Bordino P, Kraus S, Albareda D, Fazio A, Palmerio A, Mendez M, Botta S (2002) Reducing incidental mortality of franciscana dolphin Pontoporia blainvillei with acoustic warning devices attached to fishing nets. Mar Mamm Sci 18:833-842

Carlström J, Berggren P, Tregenza NJC (2009) Spatial and temporal impact of pingers on porpoises. Can J Fish Aquat Sci 66:72-82

Carretta JV, Barlow J (2011) Long-term effectiveness, failure rates, and dinner bell properties of acoustic pingers in a gillnet fishery. Mar Technol Soc J 45:7-19

Carretta JV, Barlow J, Enriquez L (2008) Acoustic pingers eliminate beaked whale bycatch in a gill net fishery. Mar Mamm Sci 24:956-961

* Chen L, Bruford MW, Xu S, Zhou K, Yang G (2010) Microsatellite variation and significant population genetic structure of endangered finless porpoises (Neophocaena phocaenoides) in Chinese coastal waters and the Yangtze River. Mar Biol 157:1453-1462

Cox TM, Read AJ, Solow A, Tregenza N (2001) Will harbour porpoises (Phocoena phocoena) habituate to pingers? J Cetacean Res Manage 3:81-86

Cox TM, Read AJ, Swanner D, Urian K (2004) Behavioral responses of bottlenose dolphins, Tursiops truncatus, to gillnets and acoustic alarms. Biol Conserv 115:203-212

Dawson SM (1994) The potential for reducing entanglement of dolphins and porpoises with acoustic modifications to gillnets. Rep Int Whal Comm Spec Issue 15:573-578

*Dawson SM, Northridge S, Waples D, Read AJ (2013) To ping or not to ping: the use of active acoustic devices in 
mitigating interactions between small cetaceans and gillnet fisheries. Endang Species Res 19:201-221

European Commission (2004) Council Regulation (EC) No $812 / 2004$ of 26.4.2004 laying down measures concerning incidental catches of cetaceans in fisheries and amending Regulation (EC) No 88/98. Off J Eur Union 47:12-31

Jefferson TA, Hung SK (2004) Neophocaena phocaenoides. Mamm Spec 746:1-12

Ju J, Yang M, Xu S, Zhou K, Yang G (2012) High level population differentiation of finless porpoises (Neophocaena phocaenoides) in Chinese waters revealed by sequence variability of four nuclear introns. Mol Biol Rep 39: 7755-7762

Kasuya T, Kureha K (1979) The population of finless porpoise in the Inland Sea of Japan. Sci Rep Whale Res Inst 31:1-44

Kasuya T, Yamamoto Y, Iwatsuki T (2002) Abundance decline in the finless porpoise population in the Inland Sea of Japan. Raffles Bull Zool 50:57-66

Kraus S (1999) The once and future ping: challenges for the use of acoustic deterrents in fisheries. Mar Technol Soc J 33:90-93

Kraus SD, Read A, Anderson E, Baldwin K, Solow A, Spradlin T, Williamson J (1997) Acoustic alarms reduce porpoise mortality. Nature 388:525

* Larsen F, Eigaard OR (2014) Acoustic alarms reduce bycatch of harbour porpoises in Danish North Sea gillnet fisheries. Fish Res 153:108-112

Larsen F, Krog C, Eigaard OR (2013) Determining optimal pinger spacing for harbour porpoise bycatch mitigation. Endang Species Res 20:147-152

Li X, Liu Y, Tzika AC, Zhu Q, Doninck K, Milinkovitch MC (2011) Analysis of global and local population stratification of finless porpoises Neophocaena phocaenoides in Chinese waters. Mar Biol 158:1791-1804

McPherson GR, Ballam D, Stapley J, Peverell S and others (2004) Acoustic alarms to reduce marine mammal bycatch from gillnets in Queensland waters: optimising the alarm type and spacing. Proc ACOUSTICS 2004, Gold Coast, p 363-368

Mei Z, Huang SL, Hao Y, Turvey ST, Gong W, Wang D (2012) Accelerating population decline of Yangtze finless porpoise (Neophocaena asiaeorientalis asiaeorientalis). Biol Conserv 153:192-200

Palka DL, Rossman MC, VanAtten AS, Orphanides CD (2008) Effect of pingers on harbour porpoise (Phocoena phocoena) bycatch in the U.S. Northeast gillnet fishery. J Cetacean Res Manage 10:217-226

R Core Team (2015) R: a language and environment for statistical computing. R Foundation for Statistical Computing, Vienna. www.r-project.org

Read AJ, Drinker P, Northridge S (2006) Bycatch of marine mammals in U.S. and global fisheries. Conserv Biol 20: 163-169

Editorial responsibility: Andrew Read,

Beaufort, North Carolina, USA
Reeves R, Wang JY (2012) Neophocaena phocaenoides. In: IUCN Red List of Threatened Species 2012: e.T41754 A17599353. http://dx.doi.org/10.2305/IUCN.UK.2012. RLTS.T41754A17599353.en (accessed 2 March 2016)

Reeves RR, McClellan K, Werner TB (2013) Marine mammal bycatch in gillnet and other entangling net fisheries, 1990 to 2011. Endang Species Res 20:71-97

Rojas-Bracho L, Reeves RR, Jaramillo-Legorreta A (2006) Conservation of the vaquita Phocoena sinus. Mammal Rev 36:179-216

Shirakihara M, Shirakihara K (2013) Finless porpoise bycatch in Ariake Sound and Tachibana Bay, Japan. Endang Species Res 21:255-262

Shirakihara K, Yoshida H, Shirakihara M, Takemura A (1992) A questionnaire survey on the distribution of the finless porpoise, Neophocaena phocaenoides, in Japanese waters. Mar Mamm Sci 8:160-164

Shirakihara M, Takemura A, Shirakihara K (1993) Age, growth, and reproduction of the finless porpoise, Neophocaena phocaenoides, in the coastal waters of western Kyushu, Japan. Mar Mamm Sci 9:392-406

Shirakihara M, Shirakihara K, Takemura A (1994) Distribution and seasonal density of the finless porpoise Neophocaena phocaenoides in the coastal waters of western Kyushu, Japan. Fish Sci 60:41-46

Shirakihara M, Seki K, Takemura A, Shirakihara K, Yoshida H, Yamazaki T (2008) Food habits of finless porpoises Neophocaena phocaenoides in Western Kyushu, Japan. J Mammal 89:1248-1256

Wang D (2009) Population status, threats and conservation of the Yangtze finless porpoise. Chin Sci Bull 54:3473-3484

Wang JY, Reeves R (2012) Neophocaena asiaeorientalis. In: IUCN Red List of Threatened Species 2012: e.T41754 A17599353. http://dx.doi.org/10.2305/IUCN.UK.2012. RLTS.T41754A17599353.en (accessed 2 March 2016)

Yoshida H, Shirakihara K, Shirakihara M, Takemura A (1995) Geographic variation in the skull morphology of the finless porpoise Neophocaena phocaenoides in Japanese waters. Fish Sci 61:555-558

พYoshida H, Shirakihara K, Kishino H, Shirakihara M, Takemura A (1998) Finless porpoise abundance in Omura Bay, Japan: estimation from aerial sighting surveys. J Wildl Manage 62:286-291

Yoshida H, Yoshioka M, Shirakihara M, Chow S (2001) Population structure of finless porpoises (Neophocaena phocaenodes) in coastal waters of Japan based on mitochondrial DNA sequences. J Mammal 82:123-130

* Zhao X, Barlow J, Taylor B, Pitman R and others (2008) Abundance and conservation status of the Yangtze finless porpoise in the Yangtze River, China. Biol Conserv 141:3006-3018

Kheng JS, Xia JH, He SP, Wang D (2005) Population genetic structure of the Yangtze finless porpoise (Neophocaena phocaenoides asiaeorientalis): implications for management and conservation. Biochem Genet 43:307-320

Submitted: April 20, 2016; Accepted: October 3, 2016

Proofs received from author(s): December 5, 2016 